\title{
Renewable Energy and Wildlife Conservation
}

\section{Research to Understand Risks, Measures Impacts, and Inform Solutions}

The renewable energy sector is rapidly expanding and diversifying the power supply of the country. Yet, as our Nation works to advance renewable energy and to conserve wildlife, some conflicts arise. To address these challenges, the U.S. Geological Survey (USGS) is conducting innovative research and developing workable solutions to reduce impacts of renewable energy production on wildlife. 


\section{Guiding Strategy}

The USGS provides scientific information and science-based options that government agencies and private industries can use as they strive to avoid, minimize, or mitigate impacts of energy infrastructure on wildlife and their habitats. Research goals range from identification of a specific local issue and options for response, to development of techniques to address nationwide concerns. Knowledge gained serves as a foundation for understanding impacts and creating workable solutions. USGS science allows for development of new or improved strategies to minimize impacts and make the national energy supply cleaner and greener.

\section{Three interrelated goals (fig. 1) are:}

1. Understand risks: Identify when, where, and why wildlife shares space with energy facilities.

2. Measure impacts: Assess direct and indirect impacts to species and populations.

\section{Inform solutions: Avoid or minimize impacts through technological fixes, management, and mitigation.}

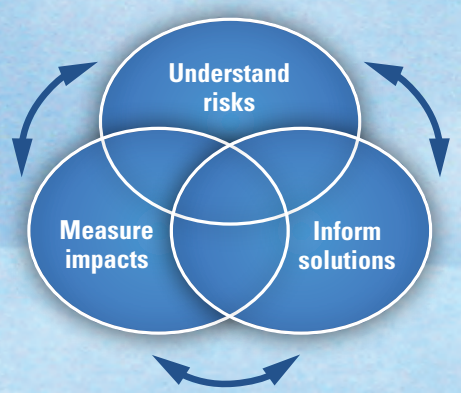

Figure 1. Three interrelated goals addressing renewable energy and wildlife.

\section{Understand Risks}

Understanding risks to wildlife starts with good information about each species of interest, including its distribution and habitat. Gaining such understanding often requires the discovery of basic biological and ecological information about each species. For example, knowing an animal's diet, migration timing and corridors, seasonal behaviors, reproductive patterns, and survival strategies helps determine when and where it might be at greatest risk from energy development. Resource managers also benefit from research that characterizes the cumulative effects of energy development throughout a species' range or over multiple generations. To get this information, scientists develop and use sophisticated tools for tracking wildlife across large distances, or for monitoring wildlife activity around energy facilities. This science helps identify which species and populations are at risk, and how and why they might be affected. This information is essential for discovering workable solutions to unacceptable risks.

\section{Causes of Bat Fatalities at Wind Turbines}

Bats provide billions of dollars in economic benefits in the United States, such as suppression of insect pests in crop fields and pollination of important desert plants (Boyles and others, 2011). However, despite dozens of bat species occurring in the United States, the lives of most remain mysterious, even to the scientists who study them. Unprecedented numbers of bats began dying at wind power facilities around the turn of the millennium, creating an imperative to understand the causes of bat fatalities at wind turbines and ultimately find solutions to this new problem. The USGS consistently contributes to discovering the underlying reasons for bat susceptibility to wind turbines by closely studying the lives of the species most

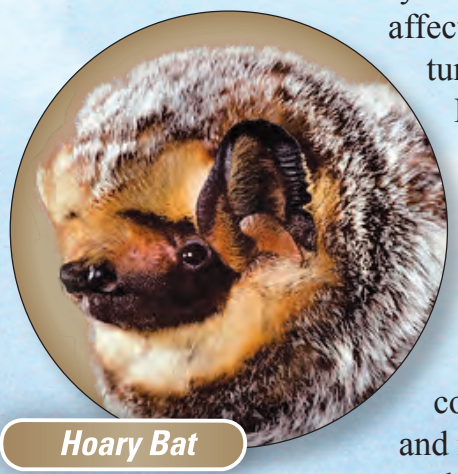
seasonal behavior drives risk. In flight, even echolocating bats perceive distant objects primarily through vision and can see in dim lighting conditions. The cumulative evidence indicates that tree bats might mistake wind turbines for trees in the dark - a potentially fatal case of mistaken identity. One solution may be to make turbines appear less like trees to bats, a 'distant avoidance' method the USGS is exploring by experimentally illuminating turbine surfaces with dim, flickering ultraviolet light that only bats can see (Gorresen and others, 2015). Another solution being explored by the USGS is to make turbines less attractive to approaching bats by emitting highfrequency sounds that interfere with bat echolocation when they get dangerously close. The USGS aims for practical solutions to the problem of bat fatalities at wind turbines.

\section{Measure Impacts}

The USGS develops tools, methods, and datasets so managers, regulators, industry, and the interested public can systematically and accurately measure the impacts of renewable energy developments on wildlife. This is essential for informing and prioritizing management actions. For example, managers and industry operators are using a statistical tool developed by the USGS to estimate wildlife fatalities at wind energy facilities (Huso and others, 2012). The USGS has developed a related tool for rare species and is adapting tools to other types of renewable energy facilities, including solar. Method and tool development commonly occurs by using energy facilities as study sites and working cooperatively with the energy industry and agency regulators.

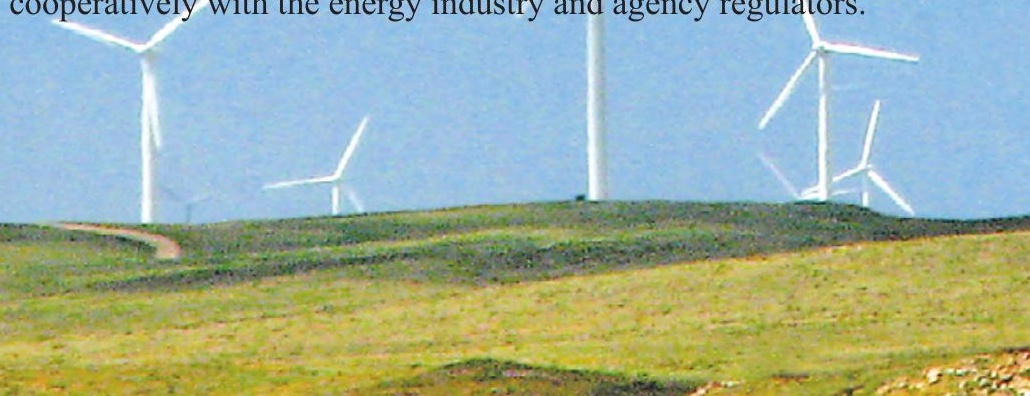




\section{Acquiring Fatality Information for Rare Species}

Wildlife managers often are concerned about collisions of rare species with turbines because this additional mortality may change the viability of a rare population. Fatality rates of rare species can be difficult to estimate simply because none or few may ever be found during periodic searches. Observing no fatalities could mean that no animals were killed, or perhaps some were killed but all carcasses were scavenged or missed in searches. The USGS, in partnership with the U.S. Fish and Wildlife Service, has developed an approach for estimating mortality even when few or no fatalities are observed (fig. 2; Dalthrop and others, 2014). The tool helps managers interpret evidence that the permitted level of take ${ }^{1}$ has not been exceeded or whether adaptive management or compensatory mitigation is needed. This tool has been helpful in the development of habitat conservation plans for wind projects, particularly in the Midwestern United States.

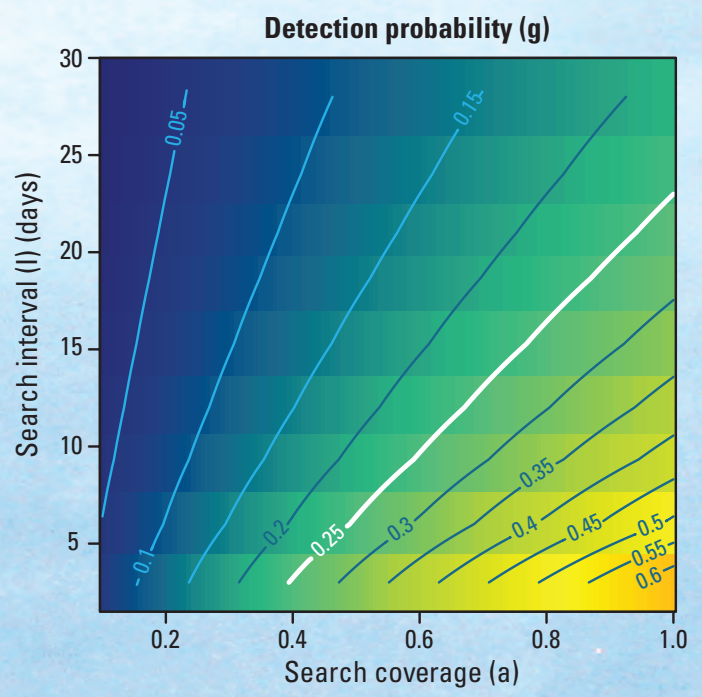

Figure 2. The tool by Dalthorp and others, 2014 helps industry operators optimize use of resources when conducting surveys for wildlife carcasses beneath wind turbines. Graphs like this are generated by the tool and help operators make choices about survey design to achieve a desired detection rate for a rare species.

\section{Inform Solutions}

Ultimately, to advance renewable energy and conserve wildlife, workable, cost-effective strategies are needed that can reduce impacts of energy development on wildlife. This may include new strategies for wildlife or habitat management, or technological solutions to avoid, minimize, or mitigate harm. The USGS has provided decades of research supporting technical

Take is defined in Section 3 of the Endangered Species Act as "harass, harm, pursue, hunt, shoot, wound, kill, trap, capture, or collect" any threatened or endangered species (Public Law 93-205, approved December 28, 1973, 87 Stat. 884). Additional policy (64 FR 607277, November 8, 1999) has clarified that harm may include significant habitat modification where it actually kills or injures a listed species through impairment of essential behavior, such as nesting or reproduction.

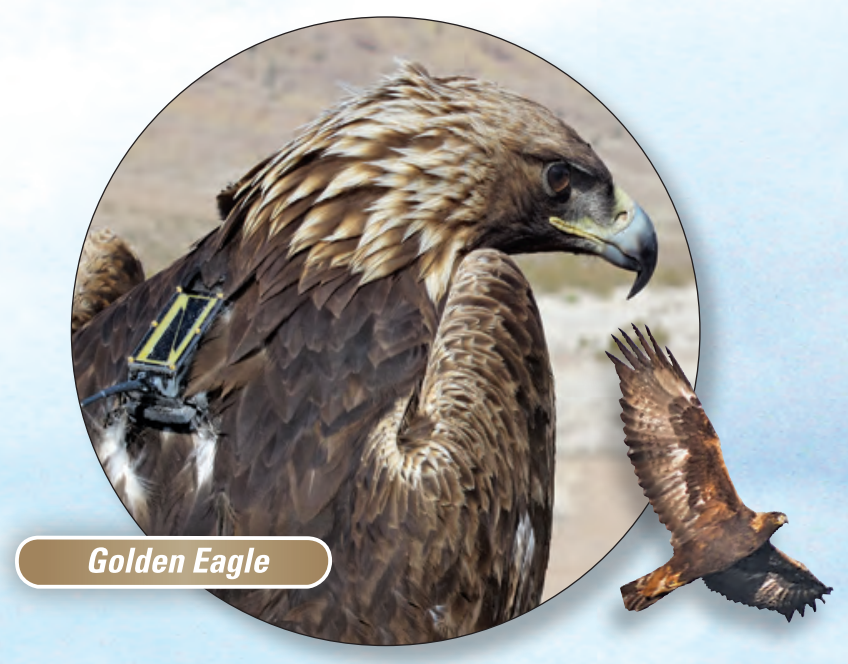

and operational solutions for hydroelectric facilities for fish passage and management of aquatic habitat. For the wind energy sector, research to inform solutions includes turbine curtailment and deterrent strategies for facilities, and preconstruction siting decision tools to minimize exposure of wildlife to risks. Additionally, data and models for estimating range-wide risks by identifying wildlife migration corridors, other habitat associations, and population trends may be useful for facility siting decisions.

\section{Forecasting Golden Eagle Fatalities}

Eagles are at the forefront of concerns about renewable energy in part because it is a Federal offense under the Bald and Golden Eagle Protection Act (16 USC 668-668c) to take an eagle without a permit. The U.S. Fish and Wildlife Service recently developed an eagle-permit process as an incentive-based mechanism that provides overall conservation benefits to eagles and, in return, grants developers and other potential permittees a degree of legal and financial certainty. The USGS has supported implementation of this process by developing a method to provide a pre-construction forecast of golden eagle fatalities at proposed wind energy facilities (New and others, 2015). This is important information because the geographic location, local topographical features, and other factors potentially play a role in the number of eagle fatalities. The forecast allows regulators to work with developers to design a wind energy facility that minimizes eagle mortality. It also is used for determining the amount of compensatory mitigation needed as a result of facility operations.

nesting or reproduction.




\section{Growth of Wind and Solar Sectors}

Renewable energy is generated using technologies that convert the natural power of wind, sun (solar), plants (biomass), Earth's heat (geothermal), and water (hydro, tidal, and hydrokinetic) into electricity. In the past decade, the scale of wind and solar energy development has expanded across the United States (fig. 3). Wind turbines now contribute to power grids in most states, and the number of utility-scale solarenergy projects is growing rapidly in the Southwest as well as in the South Atlantic Region. A significant number of large projects occur on undeveloped public lands, and new projects are anticipated to occur at an increasing rate, which can create new stress on wildlife. Because new projects often occur in or near wildlife habitat, ecological science plays an important role in helping to guide project siting and operational decisions.

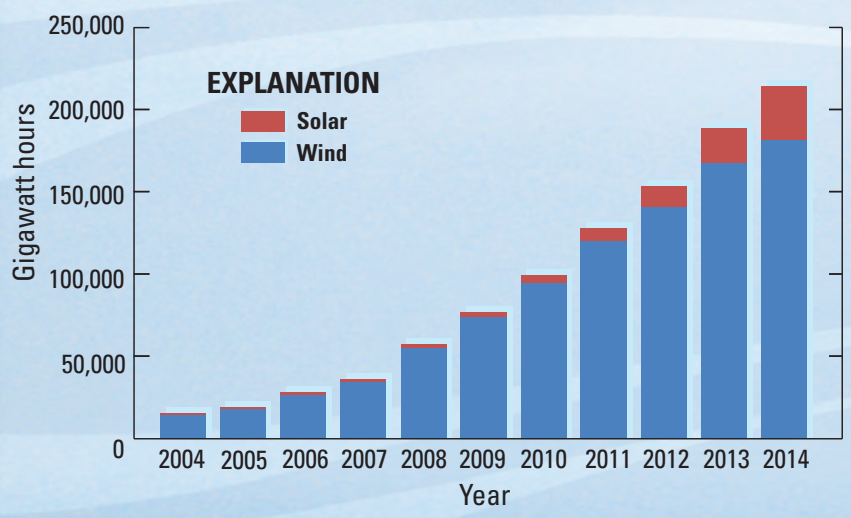

Figure 3. United States renewable electricity generation for grid-connected wind and solar power. (Source: U.S. Energy Information Agency.)

\section{Research Studies}

Boyles, J.G., Cryan, P.M., McCracken, G.F., and Kunz, T.H., 2011, Economic importance of bats in agriculture: Science, v. 332, no. 6025 , p. 41-42, doi:10.1126/science. 1201366.

Cryan, P.M., Gorresen, P.M., Hein, C.D., Schirmacher, M.R., Diehl, R.H., Huso, M.M., Hayman, D.T.S., Fricker, P.D., Bonaccorso, F.J., Johnston, D.H., Heist, Kevin, and Dalton, D.C., 2014, Behaviors of bats at wind turbines: Proceedings of the National Academy of Sciences, v. 111, no. 42, p. 15,126-15,131, doi:10.1073/pnas.1406672111.

Dalthorp, Dan, Huso, Manuela, Dail, David, and Kenyon, Jessica, 2014, Evidence of absence software user guide: U.S. Geological Survey Data Series 881, 34 p., doi:10.3133/ds881.

Gorresen, P.M., Cryan, P.M., Dalton, D.C., Wolf, S., Johnson, J.A., Todd, C.M., and Bonaccorso, F.J., 2015, Dim ultraviolet light as a means of deterring activity by the Hawaiian hoary bat Lasiurus cinereus semotus: Endangered Species Research, v. 28 , no. 3, p. 249-257, doi:10.3354/esr00694.

Huso, Manuela, Som, Nicholas, and Ladd, Lew, 2012, Fatality estimator user's guide (ver. 1.1, December 2015): U.S. Geological Survey Data Series 729, 22 p., doi.10.3133/ds729.

New, L., Bjerre, E., Millsap, B., Otto, M.C., and Runge, M.C., 2015, A collision risk model to predict avian fatalities at wind facilities - An example using golden eagles, Aquila chrysaetos: PLOS ONE, v. 10, no. 7, e0130978, doi:10.1371/ journal.pone.0130978.

\section{Author:}

Mona Khalil

For more information:

USGS Energy and Wildlife Program

https://www2.usgs.gov/ecosystems/energy_wildlife

1-800-ASK-USGS (1-888-275-8747)

Photograph credits: Hoary bat, CMerlin Tuttle.org All other images from USGS.

Publishing support provided by the U.S. Geological Survey, Science Publishing Network, Tacoma Publishing Service Center Design: William Gibbs 